\title{
DISCUSSING THE PROPRIETIES OF THE CONVENTIONAL ASSESSMENT OF FLOOD CONTROL INVESTMENT FOCUSED ON THE UNDEVELOPED AREA
}

\author{
YUKI MARUYAMA ${ }^{1}$, TAKASHI NAKAMURA ${ }^{2}$, BOUYA O. AHMED ${ }^{3}$, CHERIF O. AHMED $^{3}$, \\ KIYOKAZU UJIIE ${ }^{4}$ \& MITSUTERU IRIE ${ }^{5}$ \\ ${ }^{1}$ Graduate School of Life and Environmental Sciences, University of Tsukuba, Japan \\ ${ }^{2}$ Interdisciplinary Graduate School of Science and Engineering, Tokyo Institute and Technology, Japan \\ ${ }^{3}$ Institut Supérieur d'Enseignement Technologique, Mauritania \\ ${ }^{4}$ Faculty of Life and Environmental Sciences, University of Tsukuba, Japan \\ ${ }^{5}$ Faculty of Engineering, University of Miyazaki, Japan
}

\begin{abstract}
Large rivers running through arid regions but originating in tropical rain forests are considered as precious water resources along their riverbanks. However, upstream inundation due to flooding during the rainy season is a constraint for development. When flood control projects are proposed for such areas, technical hazards exist. To introduce a flood control project, Cost-Benefit Analysis (CBA) is used to evaluate the project's effectiveness based on computational fluid dynamics (CFD) simulation that is widely adopted for decision-making. Numerous studies applying shallow water models have focused on small urbanized areas. These studies employed fine-gridded digital elevation model (DEM) in the CFD simulation for precise evaluation. In contrast, for simulating large riverbanks of undeveloped areas, coarse-gridded DEM must be used to reduce the computational time. However, this does not consider the micromorphology. Resultantly, reproducibility of the simulation is degraded. The bank of the Senegal River was selected as our study site. Conventional CFD simulation was carried out. A coarse-gridded DEM was applied to reduce the computational time, but did not show enough reproducibility. We tried to employ General Purpose Computing on Graphics Processing Unit (GPGPU), a parallel computing method, with a fine-gridded DEM. It improved the reproducibility. In addition, the preferred conventional CBA method of the Japan International Cooperative Agency was applied to the study site. Conventional CBA was developed to assess the flood control investments mostly in urbanized areas. When applying it to undeveloped areas that have lower asset values than urbanized areas, as expected, the evaluated benefit was lower than the cost of the project. However, agricultural productivity contributes to improved food security and trade balance of the country. The flood control investment related with agricultural development should consider those externalities as benefits. This motivates us to develop an appraisal method in future research.

Keywords: flood control project, Cost-Benefit Analysis, computational fluid dynamics simulation, digital elevation model, Senegal River, GPGPU.
\end{abstract}

\section{INTRODUCTION}

Large rivers that originate upstream in tropical rain forests flow constantly, even through arid land. These precious water resources contribute to the development of settled agriculture, such as rice farming and animal husbandry along the riverbanks. However, large rivers induce not only the benefits but also constraints for such development. In the rainy season, heavy rainfall upstream raises the water level of the river and causes large-scale inundation downstream. To achieve sustainable development in developing countries, flood control projects should be proposed for stable water use.

When introducing flood control projects in such developing countries, technical issues exist. Decision-making for these projects is conducted based on the assessment of costeffectiveness [1]. Previous studies to assess the cost-effectiveness adopted Cost-Benefit Analysis (CBA) [2]-[4]. CBA is an analytical process of comparing benefits and costs in 
order to judge the cost-effectiveness [5]. Generally, CBA is conducted in combination with modelling, such as numerical simulation based on computational fluid dynamics (CFD) simulation. CFD simulation is adopted in many studies that focus on small urbanized areas. These studies give a fine-gridded digital elevation model (DEM) in CFD simulation for precise evaluation. Broekx et al. [4] conducted CFD simulation for the Flemish region's tidal portion of the Scheldt with $20 \times 20 \mathrm{~m}$ DEM mesh. Sirisena et al. [6] also adopted a $50 \mathrm{~m}$ DEM mesh in CFD simulation of the Galle Municipal Council area.

In contrast, for simulating developing countries, large riverbank areas should be considered as the simulation areas, because simulation areas comprise the regions where flood damage risk is high. However, in these countries, residential area is not concentrated to a small area. Moreover, the major industrial structure depends on the primary industries of agriculture and animal husbandry, which occur in large areas. As a solution for considering the large areas in the simulation, a coarse-gridded DEM must be employed to reduce the computational time, but then the micromorphology, such as dikes, roads, and canals, is missed. Subsequently, the accuracy of the simulation, which is evaluated by comparing the results of the simulation and the actual inundation area derived by a satellite images analysis, seems to be degraded.

In terms of the CBA, flood control benefits are assessed through the impacts of flood damage protection [7]. Emori et al. [8] compared consideration items of flood control benefit among four countries: Japan, the United States of America, the United Kingdom, and the Netherlands. As a common, protections of the direct damages such as the damage of general asset composed by the residence, office building, agricultural products are almost considered to the flood control benefit in the four countries. These direct damages are mostly dependent on the asset value. Thus, construction, such as residences and factories, has a much higher asset value than agricultural products do. The flood control benefit might be assessed lower than the cost in developing countries promoting agriculture. Additionally, protections of the indirect damages such as business suspension and emergency response delay and ripple effect of flood control represented by the farmland extensions in protection lands are hardly considered in the CBA as the benefits; instead, they are evaluated quantitatively outside the CBA in Japan. In contrast, the other three countries consider them according to project requirements. The relationship between flood damage and the regional society is difficult to reveal economically [8]. In assessing the same project per each country's process and per each decision-maker using CBA, the cost-effectiveness might be evaluated multifariously [9].

In this study, these technical hazards of CFD simulation and CBA were proved quantitatively for the regions of Mauritania that are seriously damaged by flooding using conventional modelling and an appraisal method as a case study. Additionally, we discuss these solutions, which motivates us to develop an appraisal method and numerical simulation in future research.

\section{STUDY SITE}

\subsection{Highlights of Mauritania}

Mauritania is situated in the west end of the Sahara Desert. The population is 3.1 million, and the total area is 1.03 million $\mathrm{km}^{2}$. Despite this huge amount of territory, $80 \%$ of the country is occupied by desert [10], and economic activity is limited to the regions where water resources exist. Thus, as shown by the $29 \%$ cereal self-sufficiency ratio reported for 2012 in 
the FAOstat (http://faostat3.fao.org/home/E), the food supply is mostly dependent on importation. This has been a heavy drag on development.

Yet, in recent years, the Mauritanian political situation has been stabilizing. People that evacuated to surrounding countries during the past unstable era have returned to Mauritania. In addition, the political situation of Mali, a neighboring country of Mauritania, has been serious since the occurrence of the Tuareg rebellion in 2012. These two social changes have caused a massive influx of migrants, which has led to food shortage in Mauritania.

To relieve the food shortage and dependence on importation, the Mauritanian government promotes settled agriculture along the Senegal River's banks in southern Mauritania (Fig. 1). There is potential for agricultural development in this area because of the abundant water resources.

\subsection{Senegal River}

The Senegal River is the second largest river in Africa and flows through Guinea, Mali, Senegal, and Mauritania. Its total length is $1,630 \mathrm{~km}$, its basin area is $440,500 \mathrm{~km}^{2}$, and its average annual flow rate is 24 billion $\mathrm{m}^{3}$ [11]. Its abundant river water is supplied via rainfall in highland region named as the Fouta Djallon, Guinea [12], but seasonal fluctuation of flow occurs. The Diama Dam was built in 1986 to prevent saltwater intrusion and to supply fresh water for irrigation, and the Manantali Dam, which is equipped with a hydraulic power plant, was built in 1988 to provide water resources, electricity, and river navigation at a constant water level (Fig. 1) [12], [13]. Management of the water resources and electricity is directed by the Organisation pour la Mise en Valeur du Fleuve Sénégal (OMVS), which consists of the beneficiary countries [14]. The construction of these dams was expected to be a foundation for agricultural development in Senegal and Mauritania.

However, a large amount of water flows from the headstreams of the Senegal River in Guinea during the rainy season [13]. Moreover, the Manantali Dam discharges without correct flow rate prediction of the tributaries that join the river downstream of the Manantali Dam. Therefore, river flooding is caused by increasing water level downstream, with crops before the harvesting stage sometimes being damaged after construction of the dam [14]. For example, in 1999, when large-scale flooding occurred, not only were farmlands damaged but also villages, and people also perished [15], [16].

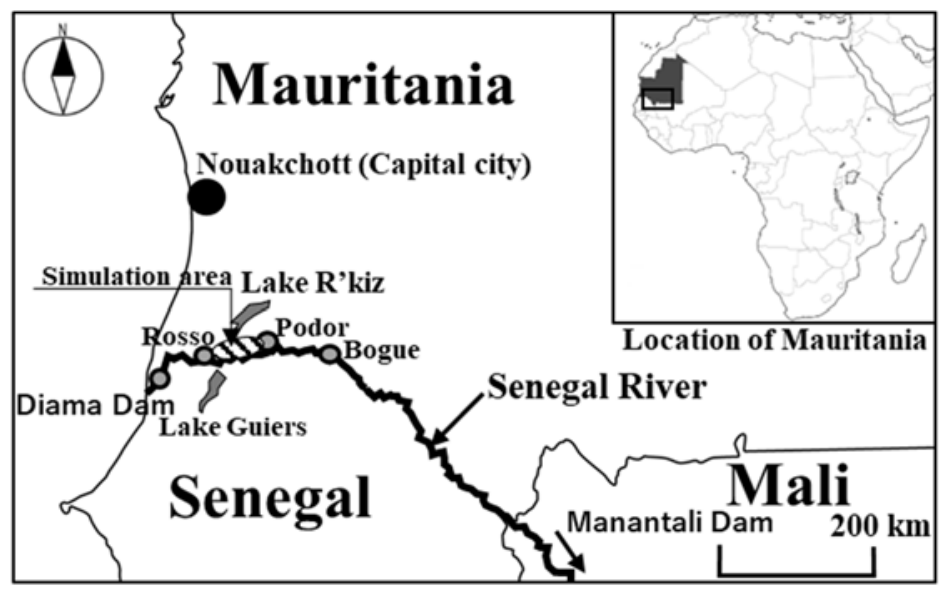

Figure 1: Location map of our study site. 


\subsection{Countermeasure to mitigate flood damage along the Senegal River}

To mitigate the flood risk to farmlands and to ensure irrigation water during the dry season, conveyance of flood water to Lake R' kiz (Fig. 2), which is a dry lake located near the Senegal River, was suggested by Irie et al. [17]. This water conveyance technique, as shown in Fig. 2 , has an effect of approximately $20 \%$ peak flow rate reduction of the Senegal River according to 32.6 million $\mathrm{m}^{3}$ of storage capacity in Lake R'kiz. Expected flood control effect was simulated via $\mathrm{CDF}$ and assessed via CBA.

\section{METHODOLOGY OF THE CFD SIMULATION AND CBA}

\subsection{CFD simulation model and boundary conditions}

iRIC Nays2Dflood was applied to our CDF simulation model. It is a 2-dimensional shallowwater flow-simulating model that considers the boundary-fitted coordinates or a rectangular coordinate system to a general curvilinear coordinate system [18]. The model runs based on eqns (1)-(5).

$$
\begin{gathered}
\frac{\partial h}{\partial t}+\frac{\partial(h u)}{\partial x}+\frac{\partial(h v)}{\partial y}=0, \\
\frac{\partial(u h)}{\partial t}+\frac{\partial\left(h u^{2}\right)}{\partial x}+\frac{\partial(h u v)}{\partial y}=-h g \frac{\partial H}{\partial x}-\frac{\tau_{x}}{\rho}+\frac{\partial}{\partial x}\left[v_{t} \frac{\partial(u h)}{\partial x}\right]+\frac{\delta}{\delta y}\left[v_{t} \frac{\partial(u h)}{\partial y}\right], \\
\frac{\partial(v h)}{\partial \mathrm{t}}+\frac{\partial(h u v)}{\partial x}+\frac{\partial\left(h v^{2}\right)}{\partial y}=-h g \frac{\partial H}{\partial y}-\frac{\tau_{y}}{\rho}+\frac{\partial}{\partial x}\left[v_{t} \frac{\partial(v h)}{\partial x}\right]+\frac{\delta}{\delta y}\left[v_{t} \frac{\partial(v h)}{\partial y}\right], \\
\frac{\tau_{x}}{\rho}=\frac{g n_{m}^{2} u \sqrt{u^{2}+v^{2}}}{h^{1 / 3}}, \\
\frac{\tau_{y}}{\rho}=\frac{\rho g n_{m}^{2} v \sqrt{u^{2}+v^{2}}}{h^{1 / 3}} .
\end{gathered}
$$

Eqns (1)-(3) indicate the equations of continuity and motion equations, respectively. For eqns (1)-(5), $h$ is water depth; $t$ is time; $u$ is flow velocity in the $x$ direction; $v$ is flow velocity in the $y$ direction; $g$ is gravitational acceleration; $H$ is water surface elevation; $\rho$ is the density of water; $\tau_{x}$ is riverbed shear stress in the $x$ direction; $\tau_{y}$ is riverbed shear stress in the $y$ direction; and $\mathrm{n}_{\mathrm{m}}$ is Manning's coefficient of roughness, which w a s assumed 0.025 in our study. Details regarding the model are explained in [19].

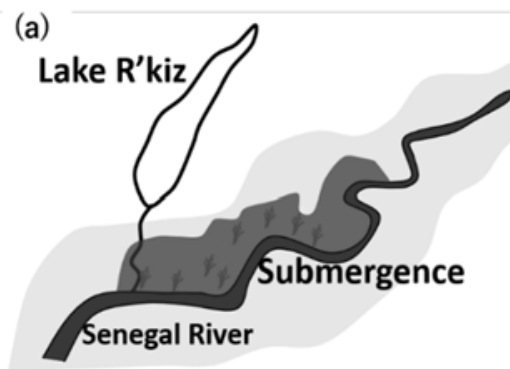

(b)

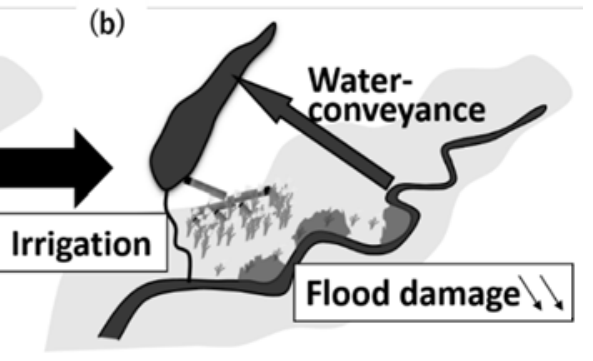

Figure 2: Diagram of the water conveyance technique for flood mitigation. (a) In the current condition, unexpected river flooding submerges farmland, and rice production is diminished; (b) In considering the water conveyance, conveying floodwater to Lake R'kiz reduces flood damage of farmlands. Stored water in Lake R'kiz is used for irrigation during the dry season. (Source: Irie et al., 2012.) 
In this model, hydraulic data inserted in the upper and lower boundaries of the river as a boundary condition and topographic data are required in order to proceed with the simulation. However, for our study site, hydraulic data is observed limited points that is Rosso and Podor [20]. Therefore, the simulation area was assumed between Rosso and Podor, accounting for about $200 \mathrm{~km}^{2}$. Additionally, although flow rates were only observed in Rosso, an upper boundary of Podor was required. To resolve this, Podor's flow rates were estimated from the Water Height-Quantity (H-Q) curve composed of flow rates in Rosso and the water level in Podor [21]. Second, a digital elevation model (DEM) was prepared from Shuttle Radar Topography Mission (SRTM) data with the mesh size of $83 \mathrm{~m}$. Corresponding to this huge simulation area, the SRTM data was averaged to $200 \mathrm{~m}$. To recognize the river, river cross sections were set in the SRTM. The cross-sectional data were assumed rectangular, owing to the lack of information, and equipped at $8 \mathrm{~m}$ depth in the normal water stage.

\subsection{CBA to assess the cost-effectiveness}

CBA was conducted by the comparing the costs and benefits with and without a flood control project to appraise the proprieties of the investment. We referred to the CBA process of the Japan International Cooperative Agency (JICA) [22], which is based on the method of the Japanese Ministry of Land, Infrastructure and Transport [7], for the assessment. Three economic evaluation indices indicated by the net present value (NPV) and benefit/cost ratio $(\mathrm{B} / \mathrm{C})$ were applied. NPV represents the difference between the present gross benefits generated by the implementation of the flood control project and the present gross cost. All of the projects produce benefits and costs during their lifetimes. However, values of the benefits and costs fluctuate depending on the time of appraisal. Thus, to compare the gross benefits and costs, all values should be converted to the same time of appraisal, which is recommended as the present time, using eqn (6).

$$
A \times \frac{1}{(1+i)^{n}}=P V
$$

where $P V$ is present value, $A$ is cost or benefit generated after $n$ years, and $i$ is the discount rate. In our study, the discount rate (i) was $12.5 \%$, as derived from the International Monetary Fund (IMF) country report [23], and the project lifetime was 50 years, based on the default of JICA [22]. The NPV is represented by eqn (7).

$$
\sum_{n=1}^{m}\left(P B_{n}-P C_{n}\right)=N P V,
$$

after $n$ years. Second, $\mathrm{B} / \mathrm{C}$ represents the present value of the gross benefits divided by the present value of gross costs. When a $\mathrm{B} / \mathrm{C}$ of more than 1 is found, a project is appraised as a high propriety for the investment.

Total cost is composed of the construction and maintenance costs. These costs were obtained from similar previous projects conducted by JICA.

Our study site was mostly occupied by paddy fields. In addition, onsite farmers practice extensive rice farming without agricultural construction and facilities. Thus, flood control benefit was only focused on the direct damage to the agricultural product, i.e., rice. This direct damage of rice was assessed via eqn (8).

$$
\mathrm{F} \times \mathrm{Y} \times \mathrm{P} \times \mathrm{D},
$$


where $\mathrm{F}$ is paddy field area (ha), as derived from the satellite image analysis using the Normalized Difference Vegetation Index (NDVI); $\mathrm{Y}$ is the average productivity ( $\mathrm{t} / \mathrm{ha}$ ); $\mathrm{P}$ is the purchasing price of paddy rice on the market; and $\mathrm{D}$ is the damage rate of the yield. Damage rate is related to the average submergence depth and the average period of submergence of the paddy fields [7]. Productivity (Y) and purchasing price (P) were identified through a questionnaire survey of the rice farmers.

"Without a flood control project" was represented by the current condition of the fields, which have a high inundation risk. In contrast, conveyance of flood water to Lake R'kiz was considered "with a flood control project". In this case, paddy fields might be extended to the flood control area, and these extensions can contribute to the enhancement of rice production. Paddy field extension was estimated as 141 ha/year based on the report of the Mauritanian Ministry of Agriculture [24] and the National Society for Rural Development (SONADER) [25]. Additionally, water conveyance channel still has the value over its lifetime. This depreciation was estimated by eqn (9) [7].

$$
\frac{\sum_{t=0}^{c-1} M_{t}}{(1+i)^{c+n}}=D P
$$

where $D P$ is the depreciation value, $M_{\mathrm{t}}$ is the maintenance cost generated after $t$ years, and $c$ is the period of the construction.

\section{RESULTS}

\subsection{Results of the CFD simulation}

First, reproducibility was evaluated by comparing the results of satellite image analysis with those of the simulation for a previous flood event in order to determine the accuracy of the simulation. Second, flood control impact was evaluated by comparing "with project" and "without project" cases, considering the return periods.

\subsubsection{Evaluating the reproducibility of CFD simulation}

Irie et al. [21] attempted to simulate the flood event of 1999, when serious flood damage occurred. However, inundation areas were not reproduced with high agreement. To improve the reproducibility, we focused on the four branch rivers generated from the mainstem Senegal River (mainstem) (Fig. 3(b)) as the factor that causes flooding.

For implementing the CFD simulation with the four branch rivers and the mainstem, data for each river's cross section and flow rates have to be considered in the simulation. A depth survey was carried out in a branch river during the normal water stage.

Each branch river was assumed $3 \mathrm{~m}$ in depth of a rectangular section, based on the assumption that all branch rivers are of the same scale.

In contrast, the three branch rivers run from the upper boundary of our study site (Fig. 3(b)). To assume the flow rates of the three branch rivers, a numerical experiment was carried out. It gave four cases of flow rates shares between the mainstem and three branch rivers indicated as the total flow rates shares by $60: 40,70: 30,80: 20,100: 0$ respectively.

As shown in Table 1, big differences did not exist among the inundation area of all simulation results, even when the flow rate was assumed only in the main channel. Additionally, reverse flow was observed at the confluence point from the mainstem to the branch rivers during field observation (Fig. 3(b)).

This supports the reverse flow supplies water from mainstem back to the branch rivers to cause the inundation. 
(a)

(b)

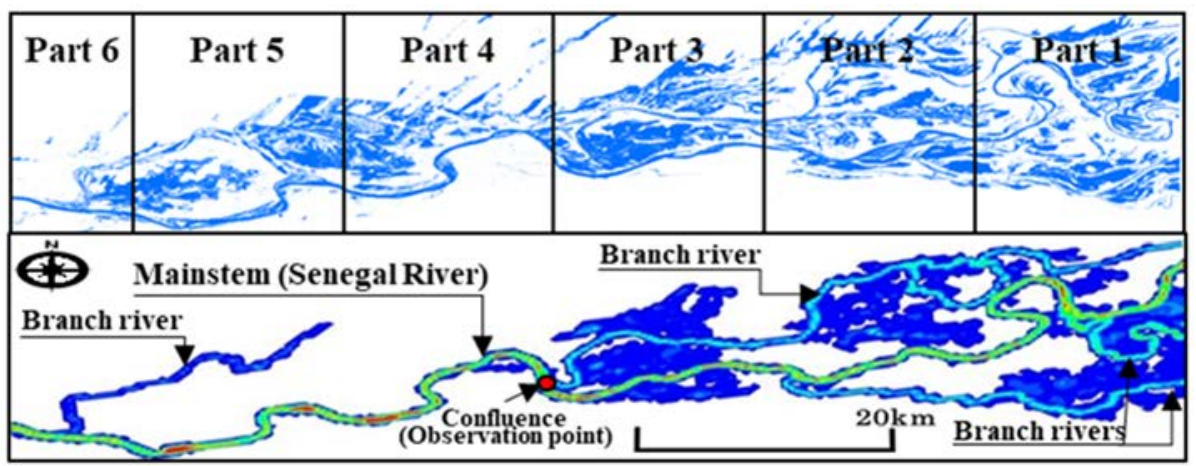

Figure 3: (a) Results of satellite image analysis divided into six parts; (b) Results of simulation.

Table 1: Results of numerical experiment.

\begin{tabular}{|c|c|c|c|}
\hline \multirow{2}{*}{} & \multicolumn{2}{|c|}{ Ratio of the flow rates shares (\%) } & \multirow{2}{*}{$\begin{array}{c}\text { Inundation } \\
\text { area (ha) }\end{array}$} \\
\cline { 2 - 3 } & Main channel & $\begin{array}{c}\text { Total shares of three } \\
\text { branch rivers }\end{array}$ & 55,928 \\
\hline Simulation 1 & 60 & 40 & 57,416 \\
\hline Simulation 2 & 70 & 30 & 59,246 \\
\hline Simulation 3 & 80 & 20 & 60,692 \\
\hline Simulation 4 & 100 & 0 & \\
\hline
\end{tabular}

Therefore, flow rates were assumed only in the main channel as a boundary condition to reproduce the reverse flow.

To evaluate the accuracy of the simulation quantitatively, results of the satellite images analysis derived using the Normalized Difference Water Index (NDWI) and NDVI [26] and results of the simulation were compared on the mesh point positions of the DEM. The number of agreements of inundation area and non-inundation area were calculated for six parts of the study area (Fig. 3) and are presented in Table 2. The agreement rate of inundation area needs to improve in future research. However, non-inundation area has high agreement for each part. Moreover, as the result of chi-square testing, all six parts were found to have relationships between the results of the satellite image analysis and the results of the simulation, at a $1 \%$ significance level. Thus, in this study, we applied the simulation with this accuracy for evaluation of the flood control impact.

Table 2: Agreement rates of the simulation.

\begin{tabular}{|c|c|c|c|c|c|c|c|}
\hline & Downstream & Part 5 & Part 4 & Part 3 & Part 2 & Upstream & Average \\
\hline $\begin{array}{c}\text { Agreement rate of } \\
\text { inundation area (\%) }\end{array}$ & 33.2 & 18.7 & 18.5 & 43.8 & 31.0 & 35.8 & 30.5 \\
\hline $\begin{array}{c}\text { Agreement rate of non- } \\
\text { inundation area (\%) }\end{array}$ & 91.7 & 87.3 & 89.6 & 84.2 & 77.3 & 71.2 & 83.6 \\
\hline Total agreement rate (\%) & 62.5 & 53.0 & 54.1 & 64.0 & 54.2 & 53. & 57.0 \\
\hline
\end{tabular}


4.1.2 Evaluation of the flood control impact of water conveyance

CDF simulation was carried out for "with project" and "without project" cases to reveal the areas protected from inundation as a flood control impact. Return periods for a wide scale of flood events were employed for evaluating the flood control impact. Return periods indicate the probability of a certain scale of flooding. As a result, the annual maximum flow rates of the upper boundary were estimated for each return period and excess probability was estimated using the exponential distribution derived from 12 years of observed flow rates in Rosso. According to this estimation, a time series of flow rates was described by each return period based on the shape of observed flow rates in 1999 (Fig. 4). A time series of water level considering the return periods was also estimated using the H-Q curve generated by the observed flow rates and water level in Rosso.

For evaluating the flood control impact, we supposed three alternatives, which were defined by three different timing regimes, to convey the river water to Lake R'kiz, which are described below.

- Alternative 1: The timing causing the inundation when flow rates of the upper boundary reach $1800 \mathrm{~m}^{3} / \mathrm{s}$.

- Alternative 2: The timing when flow rates of the upper boundary reach maximum flow rates, i.e., $2100 \mathrm{~m}^{3} / \mathrm{s}$.

- Alternative 3: The timing that changes the river condition from the normal water stage to the high water stage when flow rates of the upper boundary reach $1000 \mathrm{~m}^{3} / \mathrm{s}$.

Resultantly, we compared inundation areas (Fig. 5) and water quantity of inundations between "without project" and "with project" cases, including the three alternatives. As shown in Fig. 5, alternative 3 has the highest flood mitigation effect up to 20 years of return period, which corresponds to small-scale flood events. In contrast, alternative 1 has the highest effect for greater than 20 years of return period, such as for large-scale flood events. In terms of water quantity of inundations, the effect of flood mitigation is the same as for the inundation areas. Large-scale flood events cause physically serious harm to the rice farmers, much higher than from small-scale flood events from an economic point of view. In this study, alternative 1 was the best flood control plan.

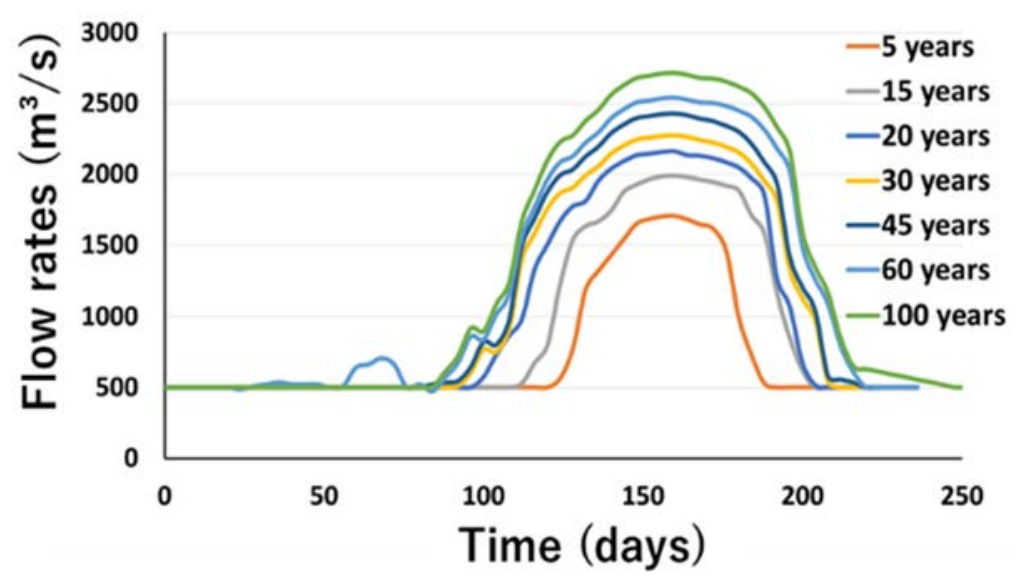

Figure 4: Time series of flow rates in upper boundary of the mainstem generated per return period. 


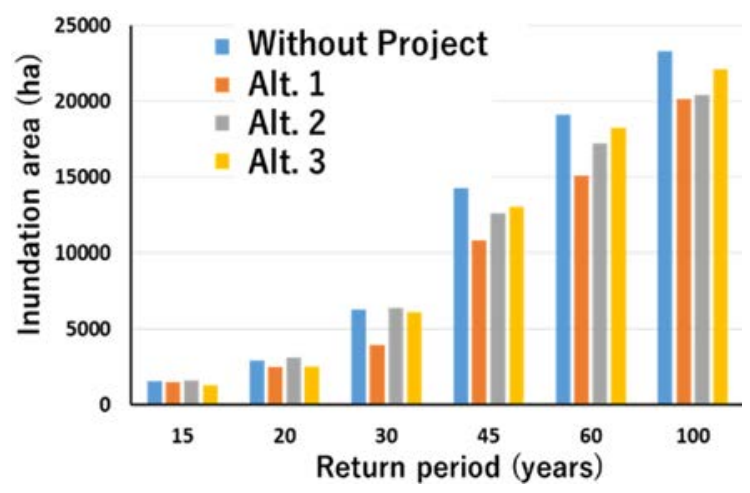

Figure 5: Comparison of the inundation area among the "without project" and three alternative cases.

\subsection{Results of the economic assessment using CBA}

According to the CFD simulation results, we assessed the economic impact of alternative 1 to decide the propriety of the investment. To assess the flood damage price of each return period, we conducted some field surveys. First, rice farmers distributed along the Senegal River were divided into three types of farmers: private farmer, cooperative farmer, and graduate farmer. A graduate farmer is one who graduates from university and manages rice farms in the M'pourie area. To these farm fields, an irrigation system has been introduced through an agricultural development project of a Chinese company. After that project was withdrawn in 2011, to ensure M'pourie was used efficiently and the graduate farmers remained employed, the government promoted use of the fields. A private farmer immigrates to engage in settled agriculture along the Senegal River with large cultivation fields. A cooperative farmer manages farmland through collaboration with local community members that have lived in the area for many years. Within our study site, cooperative farmers and private farmers are distributed in the flood risk areas. Thus, we considered these two types of farmers in the assessment, and paddy fields belonging to the cooperative farmers were identified via the location map for 2012 acquired from SONADER. As a result, paddy fields of cooperative and private farmers comprised 704 ha and 5812 ha, respectively.

The productivity and purchasing price of rice were identified via a questionnaire survey carried out in 2015 and 2016, with 156 farmers. The productivities of cooperative and private farmers were $6.7 \mathrm{t} / \mathrm{ha}$ and $5.0 \mathrm{t} / \mathrm{ha}$, respectively, in the first crop season, when a risk of flood damage exists. In terms of purchasing price, there are two types of marketing channels. The first type of market is managed by the National Society of Import and Export (SONIMEX), and had a fixed purchase price of $294.3 \mathrm{USD} / \mathrm{t}$ for paddy rice. However, total purchasing quantity was limited to $4000 \mathrm{t}$ per crop season. The second type of market is private markets. Their purchasing price fluctuated widely, from $170 \mathrm{USD} / \mathrm{t}$ to $300 \mathrm{USD} / \mathrm{t}$, depending on the season and yields.

In our study, the average purchasing price of $235.7 \mathrm{USD} / \mathrm{t}$ was applied for the private market. We assumed all produced rice was purchased in both markets.

The damage price of each return period is illustrated in Fig. 6. Flood control benefit was assessed using the difference between the "with project" and "without project" cases. Finally, the present gross benefit was calculated as the expectation value using the excess probability of return periods. 


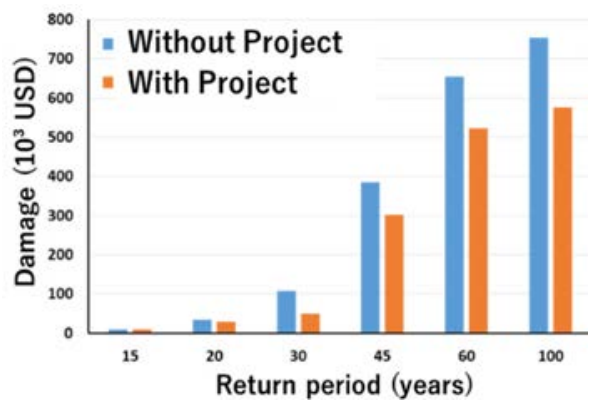

Figure 6: Comparison of the flood damage price for the "with project" and "without project" cases.

Construction cost indicates the construction fee for the $5 \mathrm{~km}$ water conveyance channel from the Senegal River to Lake R'kiz. To estimate that, a previous project of JICA, namely the Iloilo Flood Control Project, was referenced. In that project, the $4.8 \mathrm{~km}$ Halo Drainage was constructed. According to the JICA report [27], the construction cost of that water conveyance channel was estimated at 43.6 million USD over a 4-year construction period. Additionally, the maintenance cost was referenced as $246,000 \mathrm{USD} /$ year in the ex post assessment of the same project [28]. The present gross cost was assessed as 38.3 million USD using eqn (6).

As the results, the present gross cost, present gross benefit composed of the expectation value (16,200 USD) and depreciation value (108,700 USD), NPV, and B/C are indicated by 38 million USD, 0.125 million USD, -37.9 million USD and $0.33 \%$ respectively. The cost was about 300 times higher than the benefit, owing to the low expectation value of flood control benefit. Although, considering the extension impact of paddy fields, the present gross cost was about 4.4 times higher than the present gross benefit ( 8.72 million USD). Therefore, investment in flood control projects focused on agriculture in developing countries has low propriety of the investment.

\section{DISCUSSION}

\subsection{Improvement probability for the CFD simulation and problems of water conveyance}

According to the reproducibility results, agreement of the inundation area was low for all the parts. In our study site, there are many small dikes constructed by the farmers and roads on the banks with high elevation. These artificial constructions might be affected by the inundations and flood control. Additionally, some branch rivers connect to natural ponds that store river water throughout the year. These water resources are used for irrigation in the paddy fields. Many farmers construct irrigation channels connecting to these natural ponds. However, during the high water stage generated in the rainy season, river water causes inundation, even of the natural ponds and connecting irrigation channels. To express the inundation area with high reproducibility, these micromorphologies should be considered in the CDF simulation with fine grid of DEM. We tried to employ the General Purpose Computing on Graphics Processing Unit (GPGPU), a parallel computing method. The GPGPU was developed by the graphic board of a computer and has already been applied in a previous study using CFD simulation based on the 2-dimensional shallow-water equation. The GPGPU improved the computational time and the accuracy of the simulation with fine 
grid of DEM. Based on that study [29], 30 m of SRTM data was considered in the CFD simulation with the GPGPU. As shown in Table 3, agreement rates of the CFD simulation improved for all the parts. Additionally, the computational time improved from 9 days for the previous CFD simulation to 19.5 hours with the GPGPU using a Tesla P100. Therefore, implementation of the GPGPU can contribute to the evaluation of the flood control impact with higher accuracy in future research.

In terms of flood control impact of water conveyance, as shown in Fig. 5, water conveyance could not mitigate the flood significantly for any alternative. Fig. 7 illustrates the comparison of the water level at a downstream point with a 45-year return period among alternatives 1 and 3 and the "without project" case. In the case of alternative 3, the water storage capacity of Lake R'kiz was fulfilled before maximum flow rates were reached in the Senegal River. Thus, the water level was the same as for the "without project" case after 120 days. In contrast, alternative 1 reduced the water level. However, flooding could be controlled by reducing the water level up to $5.5 \mathrm{~m}$ at the survey point of Fig. 7. Reduction ability of alternative 1 was still low. This low ability of flood control was caused by the overflow dam, which was introduced at the entrance to Lake R'kiz in the water conveyance channel of the CFD simulation to regulate the timing of water conveyance. Therefore, the flow rates of overflow were too small to reduce the water level in the Senegal River dramatically.

In future studies, we need to consider alternative plans with higher flow rates, such as introduction of a sluice gate. Additionally, appropriate timing of water conveyance should be identified.

\subsection{Probability of the economic assessment, including the external effect}

Results of the CBA indicate low cost-effectiveness according to the negative NPV value and extremely low B/C percentage. As mentioned in the Introduction, the flood control benefit is mainly assessed by protections of the direct damages such as the damage of general asset of residence, office building and agricultural products in the conventional CBA. A low appraisal of the asset value of the rice affects the low propriety of this flood control investment. In the case of evaluating the impact of policy change that increases the purchasing quantity of the rice from $4000 \mathrm{t}$ to $28,000 \mathrm{t}$ on the market managed by the SONIMEX, the present gross benefit only increased by 10,000 USD. Therefore, conventional CBA did not assess the propriety as the high cost-effectiveness in our study site promoting the agriculture because of the low asset value of the agricultural products.

However, in developing counties, flood control for agricultural fields has the benefits of not only improving productivity but also of improving the domestic food supply. For some developing countries, including in Africa, much of the food supply is dependent on importation. Improvement of the food self-sufficiency ratio through flood control achieves

Table 3: Agreement rates of the simulation applied with the GPGPU.

\begin{tabular}{|c|c|c|c|c|c|c|c|}
\hline & Downstream & Part 5 & Part 4 & Part 3 & Part 2 & Upstream & Average \\
\hline $\begin{array}{c}\text { Agreement rate of } \\
\text { inundation area (\%) }\end{array}$ & 43.2 & 78.3 & 76.4 & 89.0 & 73.8 & 82.6 & 73.9 \\
\hline $\begin{array}{c}\text { Agreement rate of non-in } \\
\text { undation area (\%) }\end{array}$ & 96.3 & 75.7 & 87.7 & 86.1 & 82.5 & 76.0 & 84.1 \\
\hline Total agreement rate (\%) & 90.9 & 76.4 & 86.0 & 86.7 & 80.7 & 77.6 & 83.0 \\
\hline
\end{tabular}




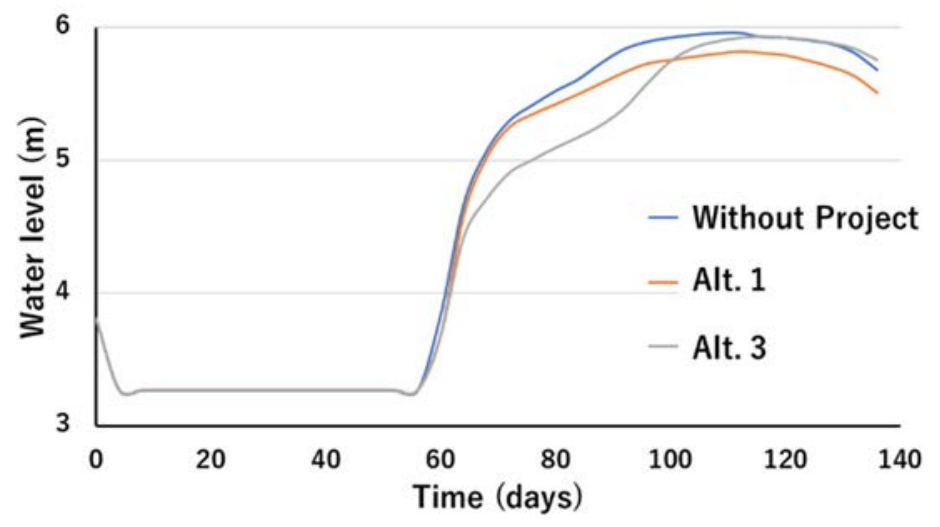

Figure 7: Comparison of the water level for the "without project" case and alternatives 1 and 2 downstream of the Senegal River.

financial condition mitigation and sustainable development [30]. These external effects should be considered in the assessment of flood control projects in order to evaluate the appropriate impact to the actual local society. In future studies, we will try to apply Computable General Equilibrium (CGE) analysis to improve the appraisal method. It could consider the wide scale of economic flows from the supply and demand points of view using an extended Input-Output table, i.e., a Social Account Matrix (SAM).

\section{CONCLUSION}

In this study, our aim was to reveal the problems of CFD simulation and CBA in the case of application to the assessment of flood control projects in developing countries with agriculture as a main industry. The CFD simulation had low reproducibility, owing to the consideration of all the widely distributed farmlands along the large river. Regarding CBA, flood control benefit focused on the agricultural fields was assessed as having low costeffectiveness, owing to the low asset value of the agricultural product. However, accuracy of the simulation improved by applying the GPGPU. Additionally, improvement of the agricultural productivity achieved by the flood control project contributed to development of the domestic food supply. This external impact should be considered in the appraisal method for flood control benefit to evaluate the appropriate impact to the actual local society.

\section{ACKNOWLEDGEMENTS}

I would like to acknowledge the professors and students of the Institut Supérieur d'Enseignement Technologique, Mauritania (iSET), who helped conduct the questionnaire survey. This work was supported by JSPS KAKENHI Grant Number JP16KT0026.

\section{REFERENCES}

[1] Matsuno, T. \& Yaguchi, T., Kaihatsu Purojecuto no Hyouka, Tsukigi Syokan: Tokyo, 1999.

[2] Mtibaa, S., Hotta, N. \& Irie, M., Analysis of the efficiency and cost-effectiveness of best management practices for controlling sediment yield: A case study of the Joumine watershed, Tunisia. Science of the Total Environment, pp. 616-617, pp. 1-16, 2018.

[3] Kind, J.M., Economically efficient flood protection standards for The Netherlands. Journal of Flood Risk Management, 7, pp. 103-117, 2014. 
[4] Broekx, S., Smets, S., Liekens, I., Bulckaen, D. \& Nocker, D.L., Designing a longterm flood risk management plan for the Scheldt estuary using a risk-based approach. Nat. Hazards, 57, pp. 245-266, 2011.

[5] Sartori, D. et al., Guide to cost-benefit analysis of investment projects: Economic approach tool for cohesion policy 2014-2020, Publication Office of the European Union: Brussels. Online. http://ec.europa.eu/regional_policy/sources/docgener/ studies/pdf/cba_guide.pdf. Accessed on: 16 Mar. 2018.

[6] Sirisena, T.A.J.G. et al., Study on flood mitigation measures: Case study Galle municipal council area. Proceedings of the 20th Congress of the Asia Pacific Division of the International Association for Hydro Environment Engineering \& Research (IAHR APD 2016), pp. 1-8, 2016.

[7] Chisui Keizai Chousa Manyual, Ministry of Land, Infrastructure and Transport, Tokyo. Online. www.mlit.go.jp/river/basic_info/seisaku_hyouka/gaiyou/hyouka/ h1704/chisui.pdf. Accessed on: 16 Mar. 2018.

[8] Emori, M. et al., A study on the benefits evaluation of social capital investment. Annual Report of RESCO, 13, pp. 19-28, 2015.

[9] Kazuhara, Y., Consideration of statistical method in flood-control planning: SLSC and cost benefit analysis. Journal of Japan Society of Civil Engineering B, 66(1), pp. 6675, 2010.

[10] World Economy Research Society, African Economic Invest in the African Economy That is Rapidly Growing, PHP: Tokyo, 2014.

[11] United Nations Educational, Scientific and Cultural Organization (UNESCO), Senegal River Basin (Guinea, Mali, Mauritania, Senegal). UN World Development Report 1, Paris, Online. www.unesco.org/new/fileadmin/MULTIMEDIA/HQ/SC/pdf/wwap_ Senegal\%20river\%20Basin_case\%20studies1_EN.pdf. Accessed on: 31 Mar. 2016.

[12] DeGeorges, A. \& Reilly, B.K., Dams and large-scale irrigation on the Senegal River: Impacts on man and the environment. International Journal of Environmental Studies, 63(5), pp. 633-644, 2006.

[13] Michael, M.H. \& Muneera, S., Development-induced food insecurity in the middle Senegal Valley. Geo Journal, 30(2), pp. 179-184, 1993.

[14] Adams, A., The Senegal River: Flood management and the future of the valley. International Institute for Environment and Development (IIED), pp. 1-31, 2000.

[15] Sandholt, I., Nyborg, L., Fog. B., Lô, M., Bocoum, O. \& Rasmussen, K., Remote sensing techniques for flood monitoring in the Senegal River Valley. Geografisk Tidsskrift-Danish Journal of Geography, 103(1), pp. 71-81, 2013.

[16] Duvail, S. \& Hamerlynck, O., Mitigation of negative ecological and socio-economic impacts of the Diama dam on the Senegal River Delta wetland (Mauritania): Using a model-based decision support system. Hydrology and Earth System Sciences Discussions, 7(1), pp. 133-146, 2003.

[17] Irie, M., Ahmed, B., Yahata, A. \& Abe, Y., Potential of improvement of agricultural production in Mauritania. Journal of Arid Studies, 21(4), pp. 143-154, 2012.

[18] Shokory, N.A.J., Tsutsumi, G.J. \& Sakai, K., Flood modelling and simulation using iRIC: A case study of Kabul City. Proceedings of the 3rd European Conference on Flood Risk Management, pp. 1-6, 2016.

[19] Takuya, I. \& Toshiki, I., Nays2D Flood Solver Manual. iRIC Project, pp. 1-25, 2012.

[20] Henny, A.F., A probabilistic design of a dike along the Senegal River. HaskoningDHV, pp. 1-150, 2012. 
[21] Irie, M., Ahmed, O.B. \& Komatsu, S., Numerical simulation of the inundation on the flood plain of Senegal River for the improvement of the agricultural productivity in Mauritania. Journal of Arid Land Studies, 25(3), pp. 121-124, 2015.

[22] Japan International Cooperation Agency (JICA), http://libopac.jica.go.jp/images/ report/11831641.pdf. Accessed on: 16 Mar. 2018.

[23] Islamic Republic of Mauritania: IMF, IMF Country Report, 15/36, www.imf.org/ external/pubs/ft/scr/2015/cr1536.pdf. Accessed on: 16 Mar. 2018.

[24] Ministry of Agriculture, Stratégie Sectorielle du Ministère de l'Agriculture Période 2015-2017, Nouakchott: Mauritania, 2014.

[25] SONADER, Rapport de la campagne d'hivernage 2013 au niveau des nouveaux perimetres, Rosso: Mauritania, 2013.

[26] Kotera, A., Nagano, T., Hanittinan, P. \& Koontanakulvong, S., Assessing the degree of flood damage to rice crops in the Chao Phraya delta, Thailand, using MODIS satellite imaging. Paddy and Water Environment, 14(1), pp. 271-280, 2016.

[27] JICA, www2.jica.go.jp/ja/evaluation/pdf/2001_PH-P230_1_s.pdf. Accessed on: 16 Mar. 2018.

[28] JICA, www2.jica.go.jp/ja/evaluation/pdf/2013_PH-P230_4_f.pdf. Accessed on: 16 Mar. 2018.

[29] Zeng, X., Akoh, R., Ishikawa, T. \& Nakamura, T., On the efficiency of GPGPU acceleration of tsunami simulations using an unstructured triangular mesh system. Journal of Japan Society of Civil Engineers Ser. B1 (Hydraulic Engineering), 69, pp. $1-6,2013$.

[30] Iraki, M., RASHINBAN. International Development Journal, 727, pp. 8-9, 2017. 